\title{
Development of Pomegranate Squash
}

\author{
Ramya $\mathrm{K}^{1}$, Logapriya $\mathrm{S}^{2}$, Priyanthi $\mathrm{S}^{3}$, Priyanka $\mathrm{S}^{4}$, Nandhini $\mathrm{A}^{5}$ \\ ${ }^{1}$ Assistant professor, Department of Agriculture Engineering, Bannari Amman Institute of technology, Tamil Nadu, India \\ 2,3,4,5 Undergraduate students, Department of Agriculture Engineering, Bannari Amman Institute of Technology, Tamil Nadu, \\ India
}

\begin{abstract}
Squash is non-alcoholic concentrated syrup used in beverage making which is usually made from fruit juices, sugar and water source. This squash has been developed from pomegranate fruit. Pomegranate has been cultivated since ancient times throughout the Mediterranean region. Being a non-seasonal fruit it is available all the year round. It contains higher levels of antioxidants. This antioxidant can help remove free radicals, protect cells from damage and reduce inflammation. The seed of pomegranate are a good source of vitamin $\mathbf{E}$ and magnesium. The pomegranate juice has three times more antioxidants than green tea and red wine. In this way we developed a healthy squash out of pomegranate. The squash also contains sugar to add some sweetness to it. Solidly it takes 20 to 25 minutes to prepare. This squash has been tested for its color, acidity, sweetness, microbial activity and sensory evaluation which gave out good results and turned out to be a successful one.
\end{abstract}

Key Words: Squash, Pomegranate, Sensory evaluation, TSS, pH.

\section{INTRODUCTION}

Punica granatum L. (Pomegranate) is a long-lived and drought-tolerant plant. Arid and semiarid zones are popular for growing pomegranate trees. They are widely cultivated in Iran, India, and the Mediterranean countries such as Turkey, Egypt, Tunisia, Spain, and Morocco.[1] However, pomegranate is categorized as a berry but it belongs to its own botanical family, Punicaceae. The only genus is Punica, with one predominant species called $P$. granatum.[8]

The trees can grow up to 30 feet in height. The leaves are opposite, narrow, oblong with $3-7 \mathrm{~cm}$ long and 2 $\mathrm{cm}$ broad. It has bright red, orange, or pink flowers, which are $3 \mathrm{~cm}$ in diameter with four to five petals. Edible fruit has a rounded hexagonal shape, with $5-12 \mathrm{~cm}$ in diameter and weighing $200 \mathrm{~g}$. The thick skin surrounds around 600 arils, which encapsulates the seeds.[9]

It was shown that pomegranate fruit could be used in the treatment of human prostate cancer because it could inhibit cell growth and induce apoptosis.[10].Out of total fruit weight $52 \%$ describes the edible part of pomegranate, comprising $22 \%$ seeds and $78 \%$ juice. The physical characteristics of pomegranate were determined as $\mathrm{Ph} 2.75$, acidity $0.35 \%$, moisture $74 \%$, carbohydrate $18.7 \%$, fibre $0.4 \%$ and fat $0.04 \%$. The iron, sodium, magnesium, copper and zinc contents in the juice were lower than that of seeds, except potassium which was found to be $49.2 \mathrm{ppm}$ in the juice. The composition of pomegranate juice depends on many factors, such as cultivar type (over thousand cultivars of Punica granatum L are known), environment, postharvest, storage and, last but not least, processing conditions.[4].

1.1 Objective

- To develop a flavored squash, this will be available all the year round.

- Nutritional quality of the squash was obtained by using pomegranate.

- To study few properties like color test, sensory test, microbial test to make the product a successful one.

\section{MATERIALS AND METHODS}

\subsection{Materials}

Squash has Pomegranate juice, Sugar, Mixer, Lemon juice, Bottle cap, Glass bottles. For the preparation of the milk the following things like muslin cloth, mixer, induction, and vessels were used. The equipment's and instruments like $\mathrm{pH}$ meter, hunters calorimeter, tray dryer, refractometer, laminar hood, L rod, petri plates, autoclave, nutrient agar were used.

\subsection{Methodology}

\subsubsection{Squash preparation}

The process is initiated pomegranate is grinded well in a mixer from which we extracted the juice and add sugar into it. It will solidly take about $15-20$ minutes to attain its consistency, until then stir the mixture well. In between this process, add few drops of lemon to it which acts as a preservative. Simultaneously, the glass bottle and their caps were sterilized for 30 minutes using an Auto clave under temperature $121^{0} \mathrm{C}$ for 20 minutes. Then the bottles were cooled to room temperature.

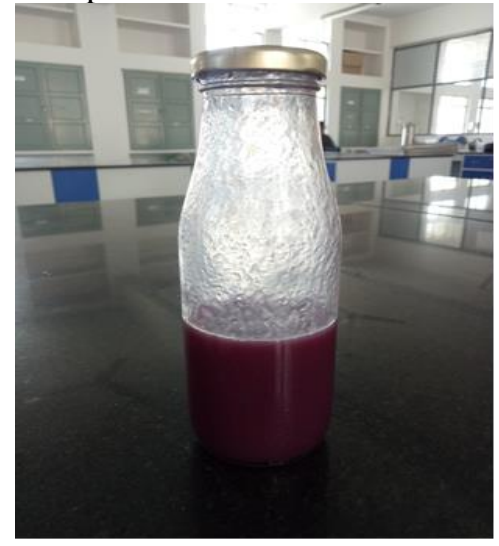

Fig -1: Pomegranate squash

\subsubsection{Color testing}

Pomegranate juice color is mainly due to the presence of anthocyanins and is influenced by product ripening, processing treatments, storage conditions, and browning reactions. Color parameters $\mathrm{L}^{*}, \mathrm{a}^{*}$, and $\mathrm{b}^{*}$ values for 
orange juice packed in cellulose active film. There were no signification differences observed among the $\mathrm{L}^{*}, \mathrm{a}^{*}$, and $b^{*}$ values of 35 days shown in (Table 1 ). The majority of samples showed slight increases in $a^{*}$ value, which indicates a redness of squash surface color.

Table -1: Color Analysis of pomegranate squash

\begin{tabular}{|c|c|}
\hline color & $\begin{array}{c}\text { Pomegranate } \\
\text { squash }\end{array}$ \\
\hline $\mathrm{L}$ & 22.44 \\
\hline $\mathrm{a}$ & 41.23 \\
\hline $\mathrm{b}$ & 31.23 \\
\hline $\mathrm{L}^{*}$ & 21.54 \\
\hline $\mathrm{a}^{*}$ & 42.33 \\
\hline $\mathrm{b}^{*}$ & 30.76 \\
\hline
\end{tabular}

\subsection{3 pH analysis}

Pomegranate squash had a $\mathrm{pH}$ value of $2.73 \pm$ 0.06 . The acidity of the fruit samples also tends to increase due to the addition of chemical preservatives [2].

\subsubsection{Total soluble solids}

The TSS of squash ranged between 47.67-44.00. The squashes having high value of TSS indicated that they have more sugar contents than those having lower value [5].

\subsubsection{Sensory Analysis}

In this evaluation the pomegranate squash was given to some members of various groups of people to evaluate the product based on their color, taste, texture, mouth feel, flavor and overall acceptability. The analysis was done based on Hedonic scale values. The values are given below, 9- Extremely liked, 8-Very much liked, 7moderately liked, 6- slightly liked, 5-Neither liked nor disliked it, 4-Slightly disliked, 3-Moderately disliked, 2Very much disliked, 1- Disliked it extremely.

Table -1: Sensory Analysis of pomegranate squash

\begin{tabular}{|c|c|c|c|c|c|c|}
\hline \multirow{2}{*}{ Descriptor } & \multicolumn{7}{|c|}{ No of persons } \\
\cline { 2 - 7 } & 1 & 2 & 3 & 4 & 5 & 6 \\
\hline Appearance & 8 & 7 & 8 & 6 & 9 & 8 \\
\hline Color & 8 & 9 & 8 & 8 & 9 & 8 \\
\hline Odour & 8 & 7 & 8 & 9 & 8 & 8 \\
\hline Taste & 9 & 9 & 8 & 9 & 9 & 9 \\
\hline Texture & 8 & 9 & 7 & 6 & 8 & 7 \\
\hline $\begin{array}{c}\text { Overall } \\
\text { acceptability }\end{array}$ & 8 & 9 & 8 & 9 & 9 & 8 \\
\hline
\end{tabular}

Based on the sensory evaluation results, pomegranates squash more acceptability over a period. But it does not cause much variation when compared to acceptability of fresh sample.

\section{CONCLUSIONS}

Even though pomegranate has high nutritional value some find difficult to peel and eat. So we have prepared a value added products (squash) from Pomegranate fruits. We have added sugar and lemon to enrich its flavor. The $\mathrm{pH}$, color, brix values gave good results. The sensory quality of pomegranate squash was acceptable till the storage period at refrigerated temperature and room temperature. The effect of storage temperatures on physicochemical, microbiological and sensory quality was less. Before the processing of fruit squashes, some factors like harvesting yields, seasonal changes and maturation must be taken into account for the production of better quality product The pomegranate fruit can be very well utilized for preparation of squash. Because these factors also significantly affect the taste profile of the final product

\section{REFERENCES}

[1] Ercisli S, Gadze J, Agar G, Yildirim N, Hizarci Y. Genetic relationships among wild pomegranate (Punica granatum) genotypes from Coruh Valley in Turkey. Genet Mol Res. 2011;10:459-64.

[2] Germain K, Benoi BK, Israel ML. Effect of ripening on the composition and the suitability for jam processing of different varieties of mango (Mangifera indica). Afr J Biotechnol 2003; 2:301-6

[3] Hrcisli S, Gadze J, Agar G, Yildirim N, Hizarci Y. Genetic relationships among wild pomegranate (Punica granatum) genotypes from Coruh Valley in Turkey. Genet Mol Res. 2011;10:459-64.

[4] Heshi, A. B., Garande, V. K., Wagh, A. N., \& Katore, H. S (2001). Effect of pre-harvest sprays of chemicals on the quality of pomegranate fruit (Punica granatum L) cv G-137. Agricultural Science Digest, 21(1), 25e27.

[5] Hussain I, Gillani SN, Khan MR, Khan MT, Shakir I. Varietal suitability and storage stability of mango squash. Int J Agri Bio 2005; 7:1038-9

[6] J. Food Sci.Kulkarni, S.G., P. Vijayan and L. Shubha. 2010. Effect of processing of dates into date juice concentrate and appraisal of its quality charac-teristics.Larmond, E. 1985

[7] Lab methods of sensory eval-uation of food. Maia, G.A. and E. Cecilia. 2002.

[8] Newman R. Sydney, Australia: Readhowyouwant; 2011. A wealth of phtochemicals. Pomegranate: The Most Medicinal Fruit (Large Print 16pt) p. 184

[9] Newman RA, Lansky EP, Block ML. Pomegranate: The Most Medicinal Fruit. Laguna Beach, California: Basic Health Publications; 2007. -A Wealth of Phytochemicals; p. 120.

[10] Rettig MB, Heber D, An J, Seeram NP, Rao JY, Liu H, et al Pomegranate extract inhibits androgen-independent prostate cancer growth through a nuclear factor-kappaB-dependent mechanism. Mol Cancer Ther. 2008;7:2662-71

[11] Storage stability of cashew apple juice preserved by hot and aseptic process. J. Food Sci.Tech. 42: 66-69.Malav, M., R. Gupta and T. Nagar. 2014. 